\title{
Life expectancy, death, and disability in Haiti, 1990- 2017: a systematic analysis from the Global Burden of Disease Study 2017
}

\author{
Fato Fene ${ }^{1}$, María Jesús Ríos-Blancas ${ }^{1}$, James Lachaud ${ }^{2}$, Christian Razo ${ }^{3}$, Hector Lamadrid- \\ Figueroa ${ }^{1}$, Michael Liư ${ }^{4}$, Jacob Michel${ }^{5}$, Roody Thermidor 6 , Rafael Lozano ${ }^{3}$
}

Suggested citation Fene F, Ríos-Blancas MJ, Lachaud J, Razo C, Lamadrid-Figueroa H, Liu M et al. Life expectancy, death, and disability in Haiti, 1990-2017: a systematic analysis from the Global Burden of Disease Study 2017. Rev Panam Salud Publica. 2020;44:e136. https://doi.org/10.26633/RPSP.2020.136

ABSTRACT Objective. To investigate the magnitude and distribution of the main causes of death, disability, and risk factors in Haiti.

Methods. We conducted an ecological analysis, using data estimated from the Global Burden of Disease Study 2017 for the period 1990-2017, to present life expectancy (LE), healthy life expectancy (HALE) at under 1-year-old, cause-specific deaths, years of life lost (YLLs), years lived with disability (YLDs), disability adjusted life-years (DALYs), and risk factors associated with DALYs.

Results. LE and HALE increased substantially in Haiti. People may hope to live longer in 2017, but in poor health. The Caribbean countries had significantly lower YLLs rates than Haiti for ischemic heart disease, stroke, lower respiratory infections, and diarrheal diseases. Road injuries were the leading cause of DALYs for people aged 5-14 years. Road injuries and HIVIAIDS were the leading causes of DALYs for men and women aged 15-49 years, respectively. Ischemic heart disease was the main cause of DALYs for people older than 50 years. Maternal and child malnutrition were the leading risk factors for DALYs in both sexes.

Conclusion. Haiti faces a double burden of disease. Infectious diseases continue to be an issue, while non-communicable diseases have become a significant burden of disease. More attention must also be focused on the increase in worrying public health issues such as road injuries, exposure to forces of nature and HIV/AIDS in specific age groups. To address the burden of disease, sustained actions are needed to promote better health in Haiti and countries with similar challenges.

Keywords $\quad$ Life expectancy; death; mortality; potential years of life lost; disabled persons; Haiti.

Public health issues remain a daunting challenge in Haiti. Almost all sociodemographic and health indicators point to large differences between Haiti and its peer Latin-American-and-Caribbean countries (LAC).The under-5 mortality rate was 58.4 per 1,000 live births in 2015, while the LAC region registered 18.3 (1). Likewise, the maternal mortality ratio (MMR), estimated at 520.8 per 100,000 live births in 2015, was

\footnotetext{
National Institute of Public Health, Cuernavaca, Mexico

2 St. Michael's Hospital, Toronto, Canada $\square$ James Lachaud james.lachaud@ unityhealth.to

3 Institute for Health Metrics and Evaluation, Seattle, United States of America
}

3.6 times the second highest MMR in the region (Bolivia, 144.5 per 100,000 live births) whereas the MMR of the LAC region was 73.6 (2). The MMR in Haiti was more than three times the targeted ratio outlined by the Millennium Development Goals, which aimed to reduce MMR by three quarters by 2015. Haiti's current situation in terms of its MMR reflects the difficulty of aligning with goal three of the 2030 Sustainable Development

\footnotetext{
4 Harvard Medical School, Boston, United States of America

5 Family Health International, Port-au-Prince, Haiti

6 Ministry of Public Health and Population, Port-au-Prince, Haiti
} 
Goals, which is to reduce the global MMR to less than 70 per 100,000 live births $(3,4)$.

Despite this situation, to our knowledge, little attention has been given to measuring and analyzing trends and patterns of death, disability, and associated risk factors in Haiti, which are critical for increasing efficient resource allocation to improve the Haitian health system. Yet one of the largest barriers is the lack of appropriate health information systems, especially routinely collected vital statistics on births and deaths that could inform Haitian health policies. Despite some recent efforts to register underlying causes of deaths in-hospital, the scarce data available remain incomplete, unreliable, and unavailable since they are largely documented on paper (5).

This article will serve as a first study in producing health burden-related evidence that could directly inform policy needs with a particular focus on Haiti. Here we document burden of disease and risk factors in Haiti by sex and age groups from 1990 to 2017, while drawing parallels with other LAC countries. Specifically, we aimed to investigate the magnitude and the distribution of the main causes of death, disability, and risk factors in Haiti focusing on several indicators of life expectancy (LE), healthy life expectancy (HALE) at under 1-year-old, years of life lost (YLLs), years lived with disability (YLDs), and disability-adjusted life years (DALYs).

\section{METHODS}

\section{Overview}

We conducted an ecological analysis of the main causes of death, disability, and risk factors in Haiti for the period 19902017. Analysis was based on public data from the Global Burden of Disease (GBD) Study 2017. Exhaustive methods on the GBD 2017 for data estimates have been previously published (6-8). In this paper, we describe these methods briefly, as there were no significant modeling changes between GBD 2016 and GBD 2017. Uncertainty estimates are maintained throughout the modeling process using 1,000 draws and 95\% uncertainty interval (UI) were calculated as 2.5th and 97.5th percentiles of the posterior distribution. Furthermore, GBD 2017 complied with the Guidelines for Accurate and Transparent Health Estimates Reporting (GATHER) (9). The UI is the equivalent name of a confidence interval when using a Bayesian approach.

The estimation of burden of disease was adjusted by sociodemographic index (SDI), a composite measure of development proposed by IHME that accounts for fertility, education, and income. We presented the life expectancy (LE) and healthy life expectancy (HALE) at under 1-year-old in both sexes, 19902017. The LE is defined as the number of years a person is expected to live based on his/her first year of birth (10). The HALE provides information about the number of years that a person at a given age can expect to live in good health, taking into account mortality and disability risks $(10,11)$. In general, there are three main components of methodology: estimation of mortality, morbidity or nonfatal health outcomes, and risk factors.

\section{Mortality}

Within the GBD study, the mortality component comes from five types of data sources: vital registration system, sample registration system, household surveys, censuses, and Demographic Surveillance Sites (DSS) (6). The main sources for Haiti were 27 vital registrations from the World Health Organization (WHO) from 1980 to 2004, 9 surveys from 1953 to 2014 conducted by the Demographic and Health Surveys Program (DHS) and the United Nations Statistics Division (UNSD), and 2 censuses from 1957 and 1978. More details about data sources for GBD Haiti are publicly available at the Global Health Data Exchange (GHDx) (12).

All-cause mortality for under-5 and 15-59 years old were estimated, from which life tables for all locations and years were produced. Fatal discontinuities and mortality due to HIV were addressed separately. The former are events that affect longterm mortality trends, such as epidemics, natural disasters, major technological or transportational accidents, war, and terrorism. For the latter, HIV in countries with large epidemics and incomplete vital registration were addressed using the Estimation and Projection Package (EPP), which is a Bayesian model developed by UNAIDS (6).

For cause of death estimation, deaths assigned by the International Classification of Diseases (ICD) that are intermediate or cannot be considered as underlying causes (garbage codes), were first redistributed using algorithms. Then, to generate 282 cause specific estimates, statistical modeling tools, such as the Cause of Death Ensemble model (CODEm), was used. CODEm is designed to test and combine results of models using a covariate selection algorithm and subsequently to weigh these models based on their out-of-sample predictive validity. To establish estimates consistent with all-cause mortality, cause of death correction procedure (CoDCorrect) was used, allowing us to rescale the sum of cause-specific estimates to equal all-cause mortality distribution (7). The indicator used in the case of mortality is YLL, which provides information about premature death and was calculated as the sum of each death multiplied by the standard life expectancy at each year (6). We presented the first 15 causes of age-standardized YLL rates for Haiti in comparison to Caribbean countries with at least 1 million inhabitants (Haiti, Cuba, Dominican Republic, Jamaica, and Trinidad and Tobago) for both sexes combined in 2017. We did not include Puerto Rico since it is an incorporated United States territory.

\section{Non-fatal health outcomes}

Within the GBD study, the prevalence and incidence for 355 diseases and injuries and 1,793 sequelae was estimated using DisMod-MR 2.1, which is a Bayesian meta-regression tool (13). For Haiti, input data included 30 surveys from 1974 to 2016 provided by DHS, Emergency Nutrition Network (ENN), WHO, etc.; 4 surveillances from 2009 to 2015, provided by WHO; 14 case notifications from 1993 to 2014, provided by WHO and the Pan American Health Organization (PAHO); one census from 2003 provided by the Haitian Institute of Statistics and Informatics (IHSI, for its name in French); among others. In-depth information is available on the GHDx (12).

YLDs were computed as the product of a prevalence estimate and a disability weight for each mutually exclusive sequelae, corrected for co-morbidities (14). More details about disability weights within the context of GBD, such as the compilation of data and disability weight construction, have been described elsewhere (15). Observed and expected age-standardized YLL 
and YLD rates were presented in the Haitian case for both sexes combined, in 1990, 2003, and 2017. This study extends over a period of 27 years, from 1990 to 2017. To present the observed and expected levels of burden in Haiti, we used three timepoints, the start year, 1990; the halfway point of the study period, 2003; and the last year, 2017.

\section{Health lost outcomes}

The metric used here was DALYs, which is computed as the sum of YLLs and YLDs (16). We presented the top 10 causes of DALYs by age in Haiti in 2017, and we calculated the percentage change with respect to 1990 .

\section{Risk factors}

The risk factors component involves the comparative risk assessment framework to estimate the levels and trends in exposure, attributable deaths, and attributable DALYs for 84 behavioral, environmental and occupational, and metabolic risks. To estimate the attributable burden for a given risk-outcome pair, three components were developed: first, to determine the metric of the cause of health loss; second, to estimate the relative risk (RR) and exposure from randomized controlled trials, cohort data, household surveys, census data, satellite data, and other sources; third, using the counterfactual level of risk factor exposure or theoretical minimum risk exposure level (TMREL) to estimate the portion of deaths, YLLs, YLDs, or DALYs that could be attributed to a given risk. In this present study, we focused on the estimation of the portion of DALYs attributable to a given risk factor.

Risk factors are counterfactual and estimated independently. As such, the sum of risk factors is not equal to $100 \%$ in a given population. Depending on the population-level exposure to each risk factor, this value might be more or less than $100 \%$. We presented the proportion of all age DALYs attributable to risk factors in Haiti in 2017 for both sexes.

The present study used only publicly available secondary sources of information without personal identifiers. Therefore, ethics approval was not required.

\section{RESULTS}

LE and HALE grew in the period analyzed. LE rose from 53.9 years (95\% UI: 52.3 to 55.5 ) and 55.1 (95\% UI: 53.6 to 56.5 ) in 1990 to 63.9 (95\% UI: 61.4 to 66.4 ) and 66 (95\% UI: 63.3 to 68.8 ) in 2017 in men and women, respectively. HALE registered an increase from 47.3 years (95\% UI: 44.9 to 49.5 ) and 47.4 (95\% UI: 44.9 to 49.8 ) in 1990 to 55.8 (95\% UI: 52.7 to 58.6$)$ and 56.8 (95\% UI: 53.6 to 59.9) in 2017 in men and women, respectively. However, Haiti experienced a decline of LE and HALE during three specific years: 1993, 2004, and 2010 (Figure 1).

The selected Carribbean countries had significantly lower age-standardized YLL rates than the national average in Haiti for 7 of the 15 causes considered. The main causes of YLLs were ischemic heart disease (3,364.4 YLLs per 100,000; 95\% UI: $2,754.4$ to $4,044.3)$, stroke $(2,950.5$ YLLs per 100,$000 ; 95 \%$ UI: $2,754.4$ to $4,044.3)$, lower respiratory infections $(2,842.9$ YLLs per 100,000; 95\% UI: 2,261.7 to 3,560.4), and diarrheal diseases (2,046.8 YLLs per 100,000; 95\% UI: 1,382.4 to 2,948.4) (Table 1). Although indistinguishable in comparison with some Caribbean countries, it should be noted that the YLL rate is high in Haiti for other causes such as road injuries $(2,035.1$ YLLs per 100,000; $95 \%$ UI: $1,380.9$ to 2,693.7) and HIV/AIDS (1,702.3 YLLs per 100,$000 ; 95 \%$ UI: $1,384.1$ to $2,150.4$ ).

Observed age-standardized YLL rates from all causes decreased in Haiti, particularly between 1990 and 2003, bringing overall YLLs closer to expected rates given the country's sociodemographic status (Figure 2). In 1990, cardiovascular diseases were responsible for the main discrepancy between observed

FIGURE 1. Healthy life expectancy (HALE) and life expectancy (LE) at under 1 year old in both sexes, Haiti, $1990-2017$

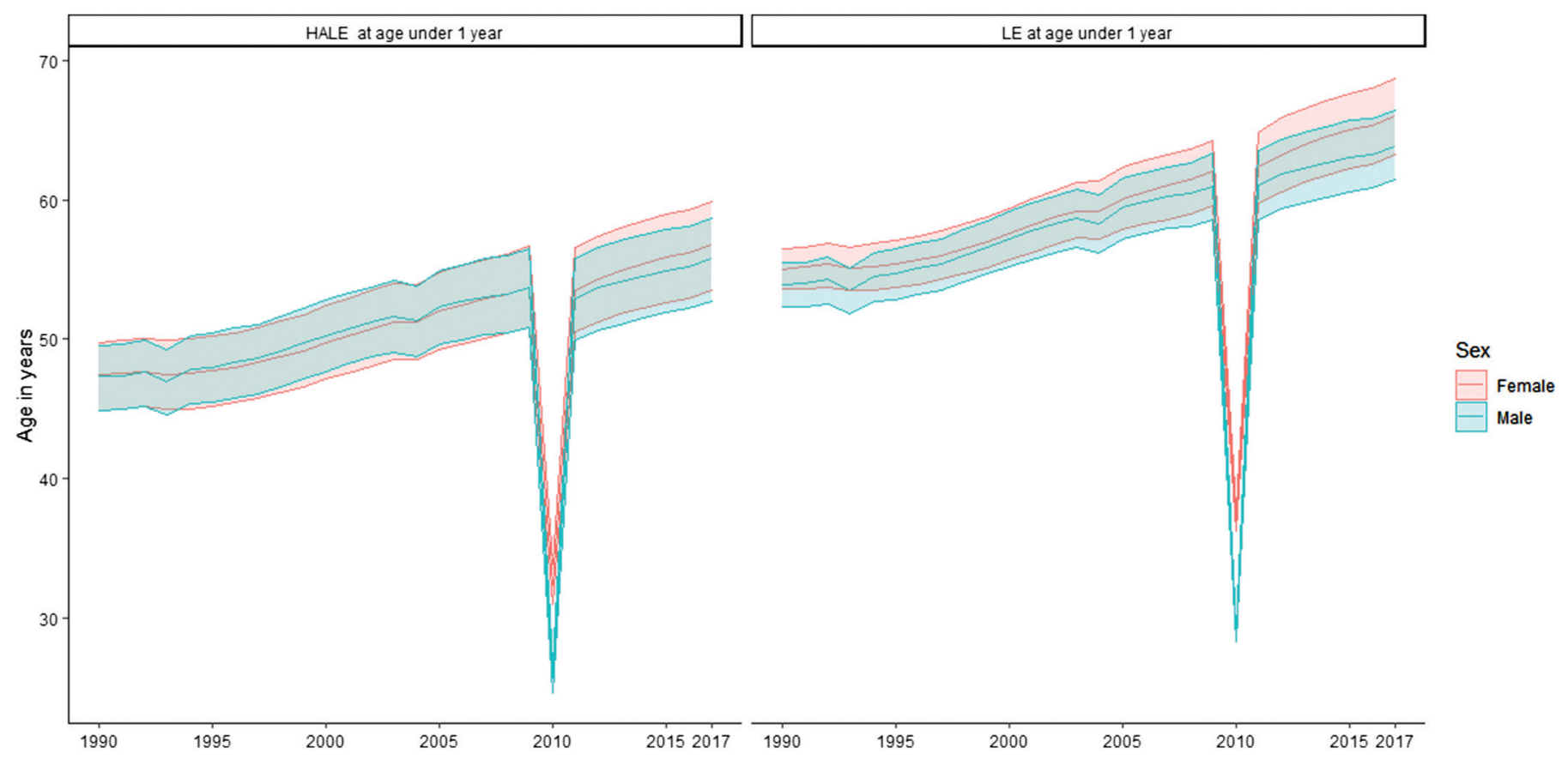




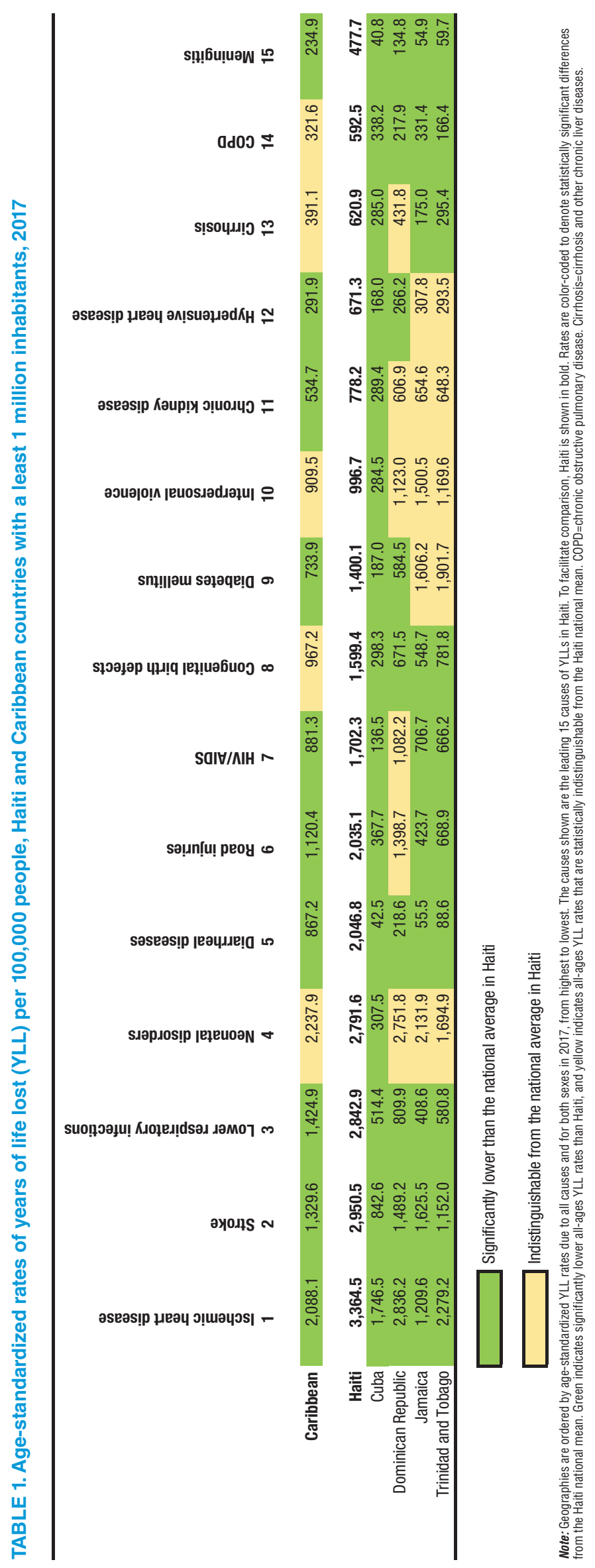


FIGURE 2. Observed and expected age-standardized rates of Years of life lost (YLL) and Years lived with disability (YLD) rates per 100,000 people, Haiti, 1990, 2003 and 2017

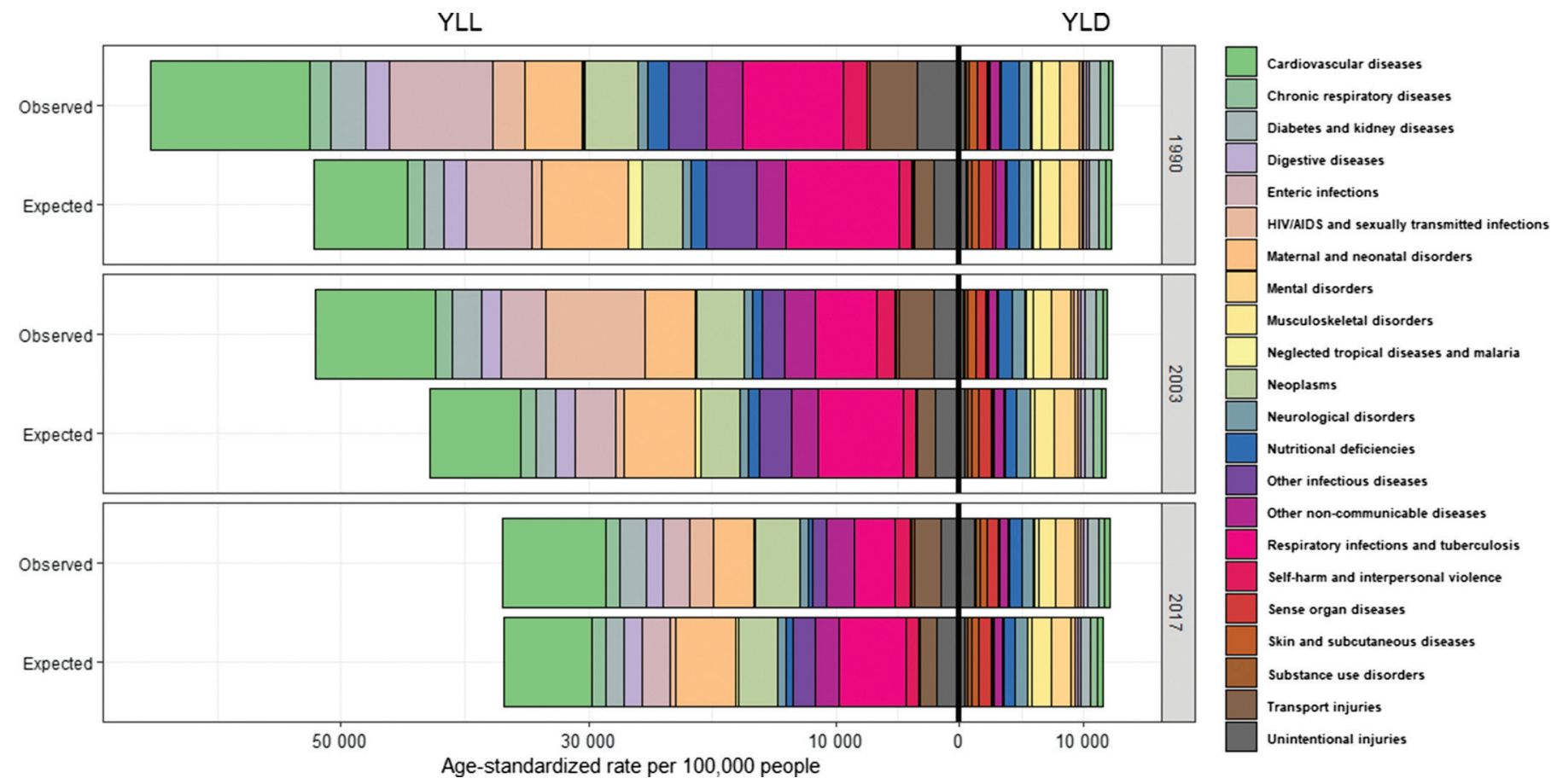

$(12,827.4$ YLLs per 100,000; $95 \%$ UI: $11,678.5$ to $14,076.3)$ and expected (7,565.3 YLLs per 100,000; without UI) YLL rates in Haiti. Other main discrepancies were found to be attributed to respiratory infections, tuberculosis, and maternal and neonatal disorders. In 2003, Haiti had higher than expected YLL rates from HIV/AIDS and sexually transmitted infections, cardiovascular diseases, neoplasms, enteric infections, diabetes, and kidney diseases. In 2017, Haiti recorded higher than expected YLLs from cardiovascular diseases, HIV/AIDS and sexually transmitted infections, and diabetes and kidney diseases. Haiti had lower than expected YLL rates from maternal and neonatal disorders, respiratory infections and tuberculosis, other infectious diseases, and neoplasms. In contrast, age-standardized YLD rates have not changed since 1990, and thus by 2017, non-fatal health outcomes accounted for a larger proportion of total DALYs than in 1990.

According to Table 2, all causes of DALYs in the under-5 age group have decreased for both sexes during the period of study. However, some causes for men and women aged 5-14 and 15-49 years have increased more than 25\% (HIV / AIDS and exposure to forces of nature). Road injuries were the leading cause of DALYs in men aged 5-14 (1,428.3 DALYs per 100,000; 95\% UI: 882.2 to $2,018.9)$ and $15-49$ years $(3,644.3$ DALYs per 100,000 ; $95 \%$ UI: $2,060.4$ to $5,629.1)$. For men, the burden of the latter age group represented 2.5 times the burden of the former in terms of road injuries. For women aged 5-14 and 15-49 years, the leading causes of DALYs were road injuries and HIV/ AIDS, respectively. It should be noted that causes of DALYs from HIV / AIDS have decreased by $0-15 \%$ among women aged $15-49$ years. The main causes in people older than 50 years were ischemic heart disease, stroke, diabetes mellitus, and prostate cancer. Unlike the other causes mentioned previously, prostate cancer increased by more than $25 \%$ for this age group.
In Haiti, the total DALYs attributable to risk factors in 2017 represented $46.9 \%$ (95\% UI: 44.2 to 49.8 ) and $49.3 \%$ (95\% UI: 46.6 to 52.2 ), respectively in men and women (Figure 3). Among behavioral risks, child and maternal malnutrition and dietary risks constituted the first and third risk factor for DALYs in men and women, respectively. In terms of environmental risks, unsafe water, sanitation, and handwashing (WASH) were the second and sixth risk factors for DALYs in men and women, respectively. Air pollution in turn represented the seventh risk factor for DALYs in men and the fifth in women. Regarding metabolic risks, high fasting plasma glucose was the fifth risk factor for DALYs in men (5.7\% of total of DALYs, 95\% UI: $4.6 \%$ to $7 \%$ ) and the second in women (8.9\% of total of DALYs, $95 \%$ UI: $7.3 \%$ to $10.9 \%$ ) in 2017 . High systolic blood pressure represented the sixth risk factor for DALYs in men (5.6\% of the total of DALYs, 95\% UI: $4.4 \%$ to $6.7 \%)$ and the fourth in women $(7.4 \%$ of the total of DALYs, 95\% UI: 5.8\% to 8.9\%) in 2017.

On the other hand, the burden of maternal and neonatal disorders was attributable to behavioral risks such as child and maternal malnutrition $(8.2 \%$ and $7.8 \%$ of the total of DALYs in men and women respectively). Cardiovascular diseases were mainly due to metabolic risks such as high systolic blood pressure $(5.1 \%$ and $6.8 \%$ of total of DALYs in men and women respectively) and behavioral risks such as dietary risks $(4.9 \%$ and $6.5 \%$ of total of DALYs in men and women respectively). Note that the UIs relevant to the percent of DALYs in the last cases were not found in the online GBD Compare database. All data used in the study are available from the authors by request.

\section{DISCUSSION}

We documented the burden of disease in Haiti focusing on LE, death, disability, and risk factors. Over the period 
TABLE 2. Top 10 causes of Disability Adjusted Life-Years (DALYs) by age and percentage temporal change, Haiti, $1990-2017$

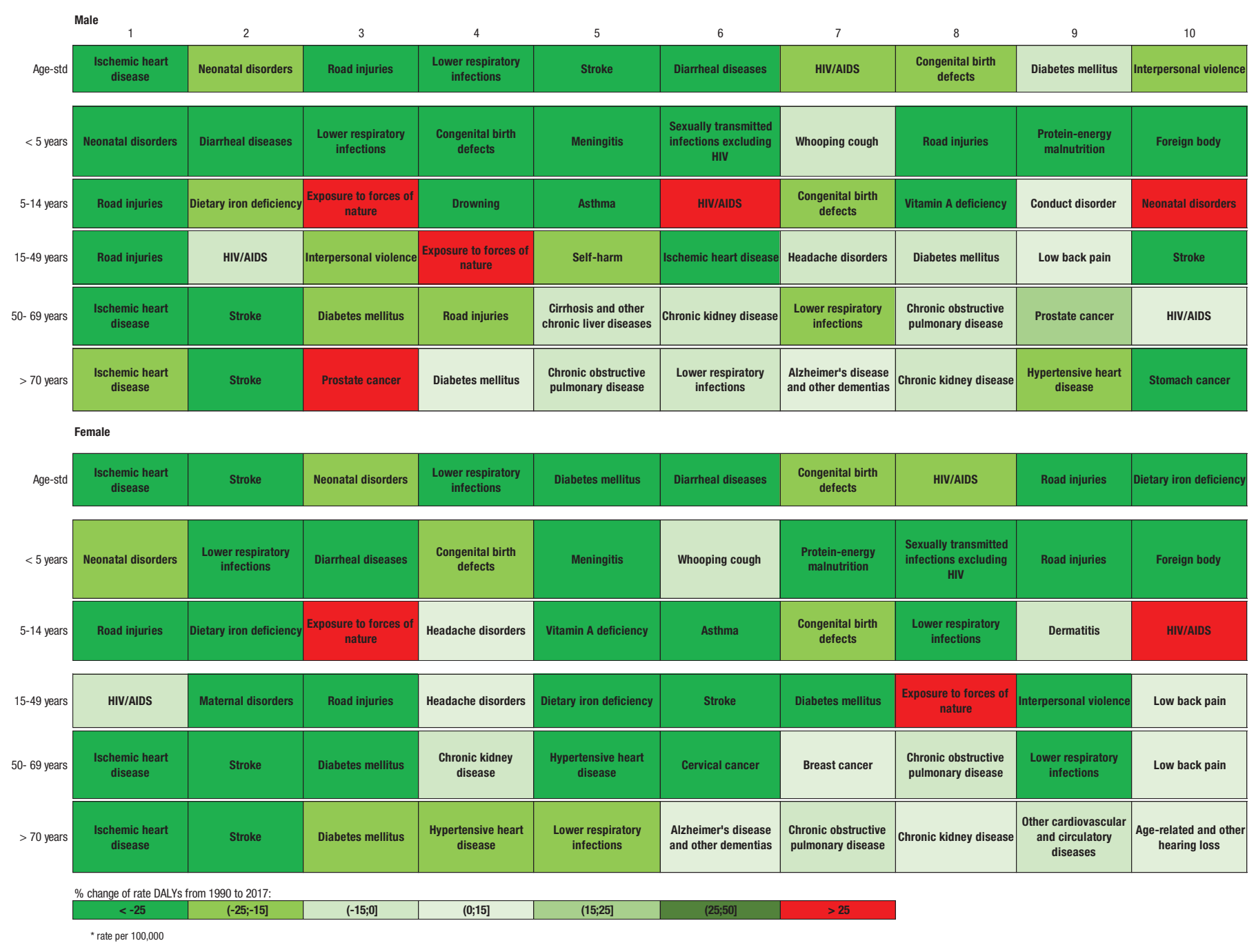

1990-2017, both LE and HALE increased substantially, though they remained lower in Haiti compared to other LAC countries. However, HALE has increased less than LE during the period 1990-2017. This result indicates that people in Haiti at under 1-year-old may hope to live longer in 2017 (nearly 10 years more than those at age under 1 year in 1990) but will spend eight of these 10 years in poor health. The evolution of LE and HALE was similar in both sexes. Despite this overall upward trend, we observed a significant rapid decrease of LE and HALE at three specific years over this period in 1993, 2004, and 2010, reflecting potential impacts of political instability and recurrent natural disasters in health conditions and Haitian health system.

In the 1991-1992 period, there was a wave of violence and deterioration of life conditions due to the economic embargo after a coup d'état to overthrow the then-elected President, Jean Bertrand Aristide (17). In the 2003-2004 period, Jean Bertrand Aristide, who was re-elected in 2000, was forced to resign before the end of his second five-year term (18). Finally, in 2010 there was a large drop in LE and HALE due to the earthquake that occurred on January 12, 2010, which killed an estimated 200,000 people and left many others disabled (19). Surprisingly, the results showed no residual effects of the earthquake on LE, despite the severe damage to water and sanitation infrastructures and health facilities. Possible explanations for the minimal residual effects of the earthquake could be attributed to the speed and scope of the humanitarian response, which facilitated access to water, sanitation, food, and healthcare (20).

This study also showed that YLLs have decreased in Haiti over the 1990-2017 period. This improvement has been driven by the relative decrease in mortality attributable to infectious diseases, which were the leading causes of deaths in 1990; this reflects the success of the national program for the control of diarrheal diseases and the introduction of oral rehydration solution (ORS), which contributed to the reduction of infantile mortality from $144 / 1,000$ in 1980 to $60 / 1,000$ in $2000(21,22)$. Despite this important improvement, Haiti still showed poorer health outcomes in 2017 when compared to some Caribbean countries. Chronic diseases such as ischemic heart disease and stroke became the leading causes of death in Haiti, and 
FIGURE 3. Disability adjusted life-years (DALYs) attributed to the Global Burden Disease risk factors for males and females, Haiti, 2017

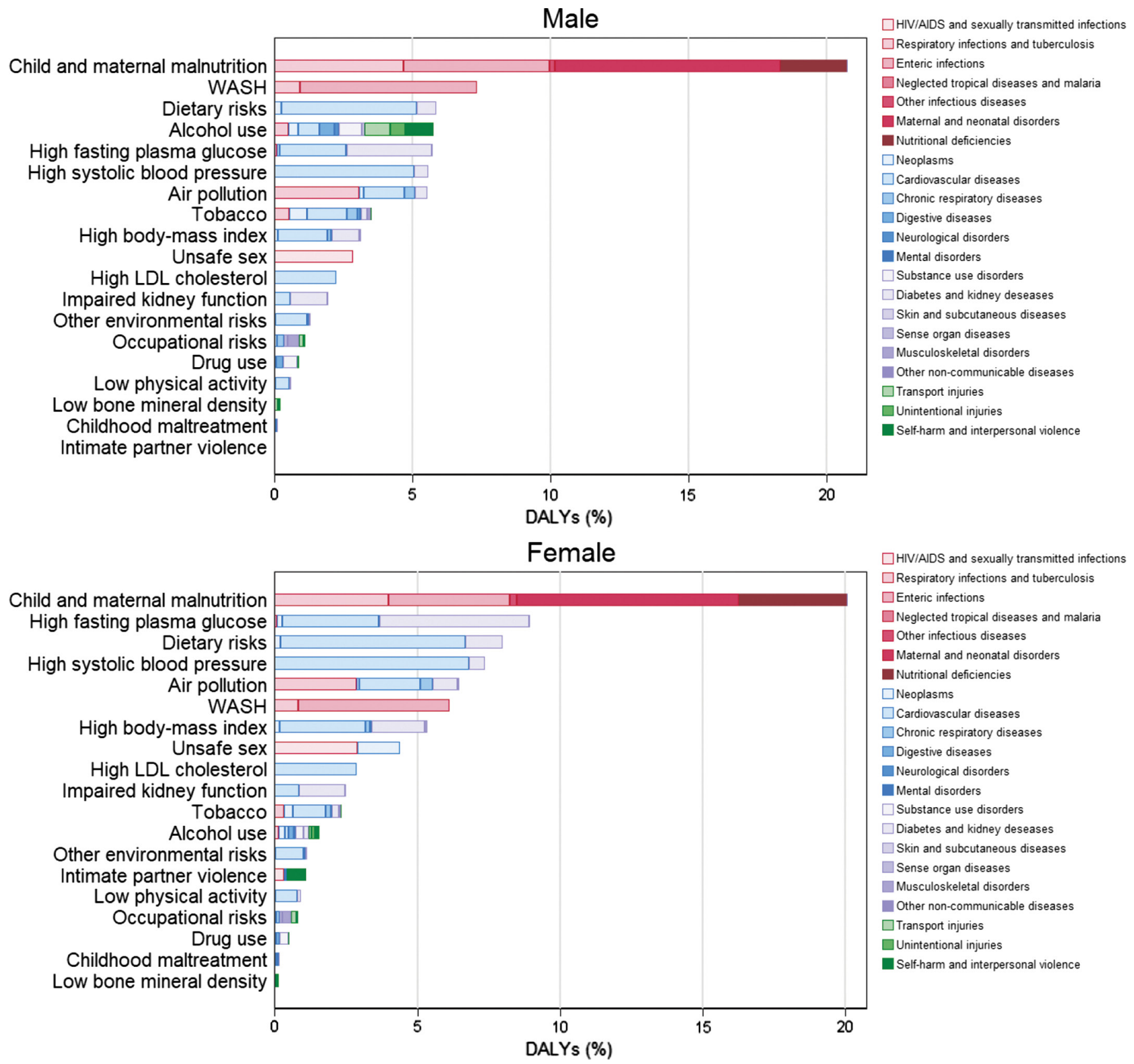

infectious diseases such as diarrhea still ranked as the fifth leading cause of YLLs in Haiti in 2017, resulting in a double burden of disease. These results are consistent with other studies in developing countries where the leading causes of death are ischemic heart disease and cerebrovascular disease (23). A previous study also classified diarrheal diseases as the fourth leading cause of YLLs in Haiti in 2017 (24). These results are similar to those found by previous studies on LAC countries $(16,25)$.

Our analysis by sex revealed that HIV/AIDS was the leading cause and second leading cause of DALYs for men and women aged 15-49 years in Haiti in 2017, respectively. This result might be explained by an increased prevalence of unprotected sexual intercourse attributable to poor socioeconomic conditions and gender-based violence (26). It is important to highlight that HIV/AIDS and exposure to forces of nature as cause of DALYs have increased substantially, in particular more than $25 \%$ during the period of study among 5-14 years old for both sexes. The lack of prevention of mother-to-child transmission could be at the root of the rise of HIV-AIDS in this age group (27). Moreover, exposure to a traumatic event such as the earthquake in 2010 could have led to adverse psychological effects, contributing to non-fatal DALYs among this age group (28). 
Another point to highlight is the magnitude of road injuries in Haiti. Road injuries ranked sixth among the main causes of YLLs and are the leading causes of DALYs for both sexes aged 15-49 years old in 2017. Previous studies have drawn attention to the proliferation of motorcycles that are sometimes operated illegally and/or driven by inexperienced individuals who have not received appropriate training $(29,30)$.

\section{LIMITATIONS}

This study is subject to all the limitations of the GBD methodology, which have been reported elsewhere $(6,16)$. Insufficient and unavailable comprehensive vital registration data and the delay of a population census to date (which was due in 2013) are challenges for data estimation in Haiti. With relatively few datapoints available, estimation mainly depends on the GBD Bayesian models using studies and results from regions or countries with similar socioeconomic and development patterns. Efforts to reinforce Haitian data systems to fill data gaps are urgently needed. Moreover, sub-national GBD estimates stratified by rural and urban areas are not available. Such data will be beneficial for promoting efficient policy implementation and equity because health resources in Haiti are largely concentrated in urban areas. Despite its limitations, this study provides a comprehensive overview of the level and distribution of the burden of disease in Haiti, offering a better understanding of the most pressing issues to target through local and multisectoral policies.

\section{CONCLUSIONS}

In light of these results, Haiti currently faces a double burden of disease. Infectious diseases continue to be a priority, while non-communicable diseases have become a significant burden of disease. This rise in chronic diseases can be attributable to a combination of risk factors such as dietary risks, high systolic blood pressure, high fasting plasma glucose, and air pollution which are all contributing to DALYs from several major chronic diseases, including diabetes and cardiovascular diseases. More attention must also be focused on the increase in worrying public health issues such as road injuries, exposure to forces of nature, and HIV/AIDS in specific age groups. To address the burden of disease, systemic actions and economic commitments are needed to improve the healthcare system and design tailored preventive strategies.

The results of the present study point to several policy recommendations: 1) strengthening health programs to reduce mortality related to control of diarrheal diseases, with a particular focus on poorer populations and regions without access to sanitation and water infrastructure; 2) developing prevention and promotion programs, with a focus on nutrition, lifestyle, and physical activity to attenuate the rising burden of chronic diseases; 3) preventing mother-to-child transmission of HIV by implementing effective maternal and child health interventions such as offering antiretroviral prophylaxis to infants; 4) implementing psychosocial and mental health programs to treat non-fatal health sequelae secondary to exposure to forces of nature in under-14 years old; 5) enforcing traffic laws to discourage certain violations (such as speeding, driving under the influence, and not wearing helmets and seat belts) as well as improving infrastructure and road signs to prevent road accidents; 6 ) investing in health policy and programs to address the double burden of disease in Haiti and other countries facing similar challenges.

Authors' contributions. FF, MJRB, HLF, CR, and JL conceived the idea and the study design; FF, MJRB and CR processed to data curation. FF, MJRB, CR run all analyses. All the authors discussed and interpreted the results. FF, MJRB, CR, and JL drafted the manuscript. All authors edited, critically reviewed and approved the final version.

Acknowledgements. We acknowledge the valuable efforts of the Institute for Health Metrics and Evaluation (IHME) for providing researchers and the general public data about the Global Burden of Disease.

Conflict of interests. RT is a public official of the Health Ministry in Haiti. The other authors declare that they have no competing interests

Disclaimer. The authors hold sole responsibility for the views expressed in the manuscript, which may not necessarily reflect the opinion or policy of the RPSP/PAJPH and/or PAHO.

\section{REFERENCES}

1. Wang H, Bhutta ZA, Coates MM, Coggeshall M, Dandona L, Diallo $\mathrm{K}$, et al. Global, regional, national, and selected subnational levels of stillbirths, neonatal, infant, and under-5 mortality, 1980-2015: a systematic analysis for the Global Burden of Disease Study 2015. Lancet. 2016;388(10053):1725-74. doi: 10.1016/S0140-6736(16)31575-6

2. Kassebaum NJ, Barber RM, Dandona L, Hay SI, Larson HJ, Lim SS, et al. Global, regional, and national levels of maternal mortality, 1990-2015: a systematic analysis for the Global Burden of Disease Study 2015. Lancet. 2016;388(10053):1775-812. doi: 10.1016/ S0140-6736(16)31470-2

3. Callister LC, Edwards JE. Sustainable Development Goals and the Ongoing Process of Reducing Maternal Mortality. J Obstet Gynecol Neonatal Nurs. 2017;46(3):e56-64. doi: 10.1016/j.jogn.2016.10.009

4. United Nations. Transforming our world: the 2030 Agenda for Sustainable Development. [Internet]. Geneva: UN; 2015 [cited 2019
Jul 16]. Available from: https://sustainabledevelopment.un.org/ post2015/transformingourworld/publication

5. Luckny Z, Lachaud J, Thimotée G. PRE-RAMOS Formative Assessment of Death Registration System and Death of Women [Internet]. Port-au-Prince: DDG; 2015 [cited 2019 Jul 16]. Available from: http://www.ddghaiti.com/doc/report_preramos_july_2015_ final_ddg_2.pdf

6. Dicker D, Nguyen G, Abate D, Abate KH, Abay SM, Abbafati C, et al. Global, regional, and national age-sex-specific mortality and life expectancy, 1950-2017: a systematic analysis for the Global Burden of Disease Study 2017. Lancet. 2018;392(10159):1684-735. doi: 10.1016/S0140-6736(18)31891-9

7. Roth GA, Abate D, Abate KH, Abay SM, Abbafati C, Abbasi N, et al. Global, regional, and national age-sex-specific mortality for 282 causes of death in 195 countries and territories, 1980-2017: a 
systematic analysis for the Global Burden of Disease Study 2017. Lancet. 2018;392(10159):1736-88. doi: 10.1016/S0140-6736(18)32203-7

8. Lozano R, Fullman N, Abate D, Abay SM, Abbafati C, Abbasi N, et al. Measuring progress from 1990 to 2017 and projecting attainment to 2030 of the health-related Sustainable Development Goals for 195 countries and territories: a systematic analysis for the Global Burden of Disease Study 2017. Lancet. 2018;392(10159):2091-138. doi: 10.1016/S0140-6736(18)32281-5

9. Stevens GA, Alkema L, Black RE, Boerma JT, Collins GS, Ezzati M, et al. Guidelines for Accurate and Transparent Health Estimates Reporting: the GATHER statement. Lancet. 2016;388(10062):e19-23. doi: 10.1016/S0140-6736(16)30388-9

10. Institute for Health Metrics and Evaluation. Findings from the Global Burden of Disease Study 2017 [Internet]. Seattle: IHME; 2018 [cited 2019 Jul 20]. Available from: www.healthdata.org

11. Islam MS, Mondal MNI, Tareque MI, Rahman MA, Hoque MN, Ahmed MM, et al. Correlates of healthy life expectancy in low- and lower-middle-income countries. BMC Public Health. 2018;18(1):111. doi: $10.1186 / \mathrm{s} 12889-018-5377-x$

12. Institute for Health Metric and Evaluation. Global Health Data Exchange | GHDx [Internet]. Seattle: IHME; 2018 [cited 2019 Jul 20]. Available from: http://ghdx.healthdata.org/

13. James SL, Abate D, Abate KH, Abay SM, Abbafati C, Abbasi N, et al. Global, regional, and national incidence, prevalence, and years lived with disability for 354 Diseases and Injuries for 195 countries and territories, 1990-2017: A systematic analysis for the Global Burden of Disease Study 2017. Lancet. 2018;392(10159):1789-858.

14. Institute for Health Metrics and Evaluation. Global Burden of Disease Study (GBD) 2017 Results [Internet]. Seattle: IHME; 2018 [cited 2019 Jul 20]. Available from: https:/ /http/ / vizhub.healthdata.org/ gbd-compare/

15. Salomon JA, Haagsma JA, Davis A, de Noordhout CM, Polinder S, Havelaar AH, et al. Disability weights for the Global Burden of Disease 2013 study. Lancet Glob Health. 2015;3(11):e712-23. doi: 10.1016/S2214-109X(15)00069-8

16. Hay SI, Abbafati AAAKHAC, Abbas KM, Abd-Allah F, Abera AMATAASF, Aboyans V, et al. Global, regional, and national disability-adjusted life-years (DALYs) for 333 diseases and injuries and healthy life expectancy (HALE) for 195 countries and territories, 1990-2016: a systematic analysis for the Global Burden of Disease Study 2016. Lancet. 2017;390(10100):1260-344. doi: 10.1016/ S0140-6736(17)32130-X

17. Malone D. Decision-making in the UN Security Council: the Case of Haiti, 1990-1997. Oxford: Oxford University Press; 1998. doi: 10.1093/acprof:oso/9780198294832.001.0001

18. Belan C. Aristide: ¿Héroe o villano? Apuntes para la historia reciente de la política en Haití (1980-2004). Rev Int História Política e Cult Jurídica. 2017;9(2):330-49. doi: 10.15175/1984-2503-20179209

19. Vargas LRD. Terremoto en Haití: las causas persistentes de un desastre que no ha terminado. Nueva Sociedad. 2010;(226):13-19.
https://biblat.unam.mx/hevila/Nuevasociedad/2010/no226/2 pdf

20. Ho JY, Frankenberg E, Sumantri C, Thomas D. Adult Mortality Five Years after a Natural Disaster. Popul Dev Rev. 2018;43(3):467-90. doi: $10.1111 /$ padr.12075

21. Pape J, Severe P, Fitzgerald D, Deschamps M, Joseph P, Riviere C, et al. The Haiti research-based model of international public health collaboration: The GHESKIO Centers. J Acquir Immune Defic Syndr. 2014;65(1):S5-S9. doi: 10.1097/QAI.0000000000000031

22. Cayemittes $M$, Placide MF, Mariko $S$, Barrère $B$, Sévère $B$, Alexandre C. Enquête Mortalité, Morbidité et Utilisation des Services, Haïti, 2005-2006. Pétion-ville \& Calverton: MSPP, IHE \& Macro International; 2007. Available from: https://dhsprogram.com/pubs/pdf/ fr192/fr192.pdf

23. Boutayeb A, Boutayeb S. The burden of non communicable diseases in developing countries. Int J Equity Health. 2005;4(2):1-8. doi: 10.1186/1475-9276-4-2

24. Naghavi M, Abajobir AA, Abbafati C, Abbas KM, Abd-Allah F, Abera SF, et al. Global, regional, and national age-sex specifc mortality for 264 causes of death, 1980-2016: A systematic analysis for the Global Burden of Disease Study 2016. Lancet. 2017;390(10100):1151210. doi: 10.1016/S0140-6736(17)32152-9

25. Vos T, Allen C, Arora M, Barber RM, Brown A, Carter A, et al. Global, regional, and national incidence, prevalence, and years lived with disability for 310 diseases and injuries, 1990-2015: a systematic analysis for the Global Burden of Disease Study 2015. Lancet 2016;388(10053):1545-602. doi: 10.1016/S0140-6736(16)31678-6

26. Martin SL, Curtis S. Gender-based violence and HIV / AIDS: Recognising links and acting on evidence. Lancet. 2004;363(9419):1410-1. doi: 10.1016/S0140-6736(04)16133-3

27. Pegurri E, Konings E, Crandall B, Haile-selassie H. The Missed HIV-Positive Children of Ethiopia. PLoS One. 2015;10(4):1-10. doi 10.1371/journal.pone.0124041

28. Tiberi O. Mental Health in Haiti: Beyond Disaster Relief. J Glob Health. 2016;6(2):14-20. https://www.ghjournal.org/ mental-health-in-haiti-beyond-disaster-relief/

29. Zuraik C, Sampalis J. Epidemiology of Traumatic Injuries at an Urban Hospital in Port-au-Prince, Haiti. World J Surg. 2017;41(11):2674-80. doi: $10.1007 /$ s00268-017-4088-2

30. McLaughlin N, Rogers H. Helping Haiti's transportation issues: Increasing Haiti's medical liabilities. J Glob Health. 2013;3(1):1-4. doi: 10.7189/jogh.03.010304

Manuscript received on 20 February 2020; revised version accepted for publication on 13 July 2020. 


\section{Esperanza de vida, mortalidad y discapacidad en Haití, 1990-2017: análisis sistemático a partir del estudio Carga Global de Morbilidad 2017}

RESUMEN Objetivo. Investigar la magnitud y la distribución de las principales causas de muerte, discapacidad y factores de riesgo en Haití.

Métodos. Se llevó a cabo un análisis ecológico con datos estimados a partir del estudio Carga Global de Morbilidad 2017 para el período 1990-2017 para presentar la esperanza de vida (LE), la esperanza de vida saludable (HALE), la mortalidad por causas específicas, los años de vida perdidos (YLL), los años vividos con discapacidad (YLD), los años de vida ajustados por discapacidad (DALY), y los factores de riesgo asociados a los DALY.

Resultados. La LE y la HALE aumentaron sustancialmente en Haití. En 2017, la población puede esperar vivir más, pero con mala salud. Los países del Caribe tuvieron tasas de YLL significativamente más bajas que Haití en cuanto a cardiopatías isquémicas, accidentes cerebrovasculares, infecciones respiratorias bajas y enfermedades diarreicas. Las lesiones debidas a accidentes de tránsito fueron la principal causa de DALY para las personas de 5 a 14 años. Las lesiones debidas a accidentes de tránsito y el VIH/sida fueron las principales causas de DALY en hombres y mujeres de 15 a 49 años de edad, respectivamente. Las cardiopatías isquémicas fueron la principal causa de DALY para las personas mayores de 50 años. Las desnutriciones materna e infantil fueron los principales factores de riesgo de DALY en ambos sexos.

Conclusión. Haití se enfrenta a una doble carga de enfermedad. Las enfermedades infecciosas siguen siendo un problema, mientras que las enfermedades no transmisibles se han convertido en una carga significativa de enfermedad. También debe prestarse más atención al aumento de problemas de salud pública preocupantes, como las lesiones por accidentes de tránsito, la exposición a fenómenos naturales y el VIH/ sida en grupos etarios específicos. Para hacer frente a la carga de morbilidad es necesario adoptar medidas sostenidas para promover una mejor salud en Haití y en los países con desafíos similares.

Palabras clave Esperanza de vida; muerte; mortalidad; años potenciales de vida perdidos; personas con discapacidad; Haití. 